\title{
A functional approach to the body condition assessment of lactating donkeys as a tool for welfare evaluation
} \author{
Antoniazzi ${ }^{2}$, Amy K Mc Lean ${ }^{4}$, Michela Minero ${ }^{5}$, Laura Cavallarin ${ }^{2}$ \\ 1 Department of Veterinary Science, University of Turin, Grugliasco (TO), Italy \\ 2 ISPA-CNR, Institute of Sciences of Food Production, Grugliasco, Italy \\ 3 The Veterinary Medical Research Institute for Piemonte, Liguria and Valle d'Aosta, Torino, Italy \\ 4 North Carolina State University, Animal Science, Raleigh, NC, USA \\ 5 Department Veterinary Science and Public Health, University of Milano, Milano, Italy \\ Corresponding Author: Emanuela Valle \\ Email address: emanuela.valle@unito.it
}

Emanuela Valle ${ }^{\text {Corresp.. }}{ }^{1}$, Federica Raspa ${ }^{1}$, Marzia Giribaldi $^{2}$, Raffaella Barbero ${ }^{3}$, Stefania Bergagna ${ }^{3}$, Sara

Background. The breeding of lactating donkeys is increasing in Western Europe; with it the evaluation of body condition is growing in importance since it is considered a key principle for their welfare. However, assessment of body condition is a complex task, since several factors are involved. The aim of the present study is to investigate which animal-based indicators are the most reliable to describe the body condition of lactating donkeys. For this purpose, new animal-based indicators, which are easy to measure in field conditions (including body measurements, fatty neck score (FNS), dental score), are recorded and their relationship with BCS (a proxy measure for overall adiposity) was assessed. The ones that reveals an associations with the BCS are included in an integrated principal component analysis to understand which are the most related to BCS. Methods. Fifty-three healthy lactating donkeys of various breeds, including 7 Martina Franca, 10 Ragusano, 2 Romagnolo and 34 crossbreeds, were evaluated. The animals based indicators that were recorded were: length (OP, olecranon tuber-pinbone and $\mathrm{SH}$, shoulder-hip), heart girth $(\mathrm{HG})$, abdominal circumference $(\mathrm{AC})$; neck length $(\mathrm{NL})$, neck height $(\mathrm{NH})$ and neck thickness (NT) at 0.50 and neck circumference (NC) at $0.25,0.50$ and 0.75 , body condition score (BCS) and fatty neck score (FNS). The owners' evaluation of the BCS was also considered. A dental assessment was performed and the month of lactation and age of each animal was recorded. Results. No correlation was found between BCS and the other morphometric body measurements. On the contrary the FNS was correlated with the morphometric measurements of the neck (positive correlation to $0.50 \mathrm{NH}$ and $0.50 \mathrm{NT}$, $0.50 \mathrm{NC}, 0.75 \mathrm{NC}$, mean and negatively correlation to the mean NC:NH and mean NC:NT, mean NC, $0.50 \mathrm{NC}$ :NT and 0.50 NC:NH ratios). A significant inverse relationship was identified between BCS and dental score. A Principal Component analysis (PCA) separated 
the BCS classes on the first principal component (PC1). PC1 revealed a meaningful positive correlation between the BCS and the neck measurements (NT, NH and FNS), with high positive loadings, while a negative correlation was found for dental abnormalities. The owners' evaluation of BCS was different from the expert evaluator' assessment, since they tended to give higher score that was slightly but significantly correlated to AC. Discussion A new scoring system, called Fatty Neck Score (FNS), has been proposed for the judgement of the adiposity status of donkey neck. The results suggest that caregivers might use the proposed animal based indicators (BCS, FNS and dental scores) together as a tool for the evaluation of the body condition of lactating donkeys. Our findings highlight that caregivers need to be trained in order to be able to properly record these indicators. Ultimately use of these indicators may help to improve the welfare of lactating donkeys. 


\section{A functional approach to the body condition}

2 assessment of lactating donkeys as a tool for welfare

3 evaluation

4 Emanuela Valle ${ }^{1}$, Federica Raspa ${ }^{1}$, Marzia Giribaldi ${ }^{2}$, Raffaella Barbero ${ }^{3}$, Stefania Bergagna ${ }^{3}$,

5 Sara Antoniazzi², Amy Mc Lean ${ }^{4}$, Michela Minero ${ }^{5}$, Laura Cavallarin²

$6{ }^{1}$ Department of Veterinary Science, The University of Torino, Grugliasco 10095, Italy

$7 \quad 2$ Institute of Sciences of Food Production (ISPA-CNR), Grugliasco 10095 Italy

$8{ }^{3}$ The Veterinary Medical Research Institute for Piedmont, Liguria and the Aosta Valley Torino

910100 Italy

$10{ }^{4}$ Animal Science, North Carolina State University, Raleigh, NC 27695

$11{ }^{5}$ Department Veterinary Science and Public Health, The University of Milano, Milano 20100

12 Italy

13

14

15

Corresponding author:

Emanuela Valle,

Largo Braccini 2, 10095 Grugliasco (To) Italy

Email address: emanuela.valle@unito.it 
27 ABSTRACT:

28 Background. The breeding of lactating donkeys is increasing in Western Europe; with it the evaluation of body condition is growing in importance since it is considered a key principle for their welfare. However, assessment of body condition is a complex task, since several factors are involved. The aim of the present study is to investigate which animal-based indicators are the most reliable to describe the body condition of lactating donkeys. For this purpose, new animalbased indicators, which are easy to measure in field conditions (including body measurements, fatty neck score (FNS), dental score), are recorded and their relationship with BCS (a proxy measure for overall adiposity) was assessed. The ones that reveals an associations with the BCS are included in an integrated principal component analysis to understand which are the most related to $\mathrm{BCS}$.

Methods. Fifty-three healthy lactating donkeys of various breeds, including 7 Martina Franca, 10 Ragusano, 2 Romagnolo and 34 crossbreeds, were evaluated. The animals based indicators that were recorded were: length (OP, olecranon tuber-pinbone and $\mathrm{SH}$, shoulder-hip), heart girth (HG), abdominal circumference (AC); neck length (NL), neck height (NH) and neck thickness (NT) at 0.50 and neck circumference (NC) at $0.25,0.50$ and 0.75 , body condition score (BCS) and fatty neck score (FNS). The owners' evaluation of the BCS was also considered. A dental assessment was performed and the month of lactation and age of each animal was recorded.

Results. No correlation was found between BCS and the other morphometric body measurements. On the contrary the FNS was correlated with the morphometric measurements of the neck (positive correlation to $0.50 \mathrm{NH}$ and $0.50 \mathrm{NT}, 0.50 \mathrm{NC}, 0.75 \mathrm{NC}$, mean and negatively correlation to the mean NC:NH and mean NC:NT, mean NC, $0.50 \mathrm{NC}: \mathrm{NT}$ and $0.50 \mathrm{NC}: \mathrm{NH}$ ratios). A significant inverse relationship was identified between BCS and dental score. A Principal Component analysis (PCA) separated the BCS classes on the first principal component (PC1). PC1 revealed a meaningful positive correlation between the BCS and the neck measurements (NT, NH and FNS), with high positive loadings, while a negative correlation was found for dental abnormalities. The owners' evaluation of BCS was different from the expert evaluator' assessment, since they tended to give higher score that was slightly but significantly correlated to AC.

Discussion A new scoring system, called Fatty Neck Score (FNS), has been proposed for the judgement of the adiposity status of donkey neck. The results suggest that caregivers might use 
58

59

60

61

62

63

64

65

66

67

68

69

the proposed animal based indicators (BCS, FNS and dental scores) together as a tool for the evaluation of the body condition of lactating donkeys. Our findings highlight that caregivers need to be trained in order to be able to properly record these indicators. Ultimately use of these indicators may help to improve the welfare of lactating donkeys.

\section{INTRODUCTION}

Donkey's milk has long been used as a substitute for human milk, and its use is related to the countries in which donkeys are traditionally bred, such as Asia, Africa and Eastern Europe (Vincenzetti et al., 2007). However, in the last 10 years, the breeding of donkeys for the production of milk has increased, as has the number of published research papers on the use of donkey milk, especially in Western Europe (http://www.gopubmed.org/). This is due to the fact that donkey milk has been demonstrated to be a useful substitute for children who are affected by allergies to the milk proteins of cows, or who suffer from multiple food intolerances (Monti et al., 2007; Monti et al., 2012). It has recently been demonstrated in vivo that dietary supplementation with donkey milk can result in a decrease in the inflammatory status of Wistar rats used as an animal model, and that this decrease is in turn associated with an improvement in the lipid and glucose metabolism, compared to a diet supplemented with bovine milk (Trinchese et al., 2015). Donkey milk also has a long tradition of cosmetic use (Faye and Konuspayeva, 2012). These potential uses of donkey milk have led to an increase in the donkey population in Western Europe, and in particular, to the number of animals that are bred in Italy (D'Alessandro e Martemucci, 2012; Cavallarin et al., 2015).

Since the breeding of lactating donkeys is increasing, it is important to evaluate their welfare. Body condition can be considered a key criterion of the overall welfare of the animals. Even though the body condition has been studied extensively, the term includes a series of concepts that are not clearly expressed in many situations. Generally speaking, the "condition" of an animal is considered as an indicator of its "individual quality" (Labocha et al., 2013). In most studies, the body condition is treated as a measure of energy reserves (mostly fat mass), but it is difficult to measure directly; in fact, direct methods, such as dilution techniques or dual-energy X-ray absorptiometry (Quaresma, et al., 2013), suffer from noteworthy limitations, since they are expensive and impractical to perform on a farm. 
89 For this reason, the body condition is inferred from several animal-based indicators that are 90 proposed to describe energy, reserves or mass of body fat; some of these indicators are

91 92 93

One of the most frequently used animal-based morphometric indicator is body condition score (BCS). This is a proxy measure of the total mass of a subcutaneous fat, know as adiposity of the body. By means of a visual appraisal and palpation of the adipose tissue sites, it is possible to rate the animal's body condition using a numerical scale (Carter and Dugdale, 2013). Different BCS scoring systems, based on 5- or 9-point scales, are also available for donkeys (Pearson \& Ouassat, 2000; Burden, 2012). Other animal-based morphometric indicators, such as direct measurements of the body or calculation of the ratio index, can be used, and could theoretically reduce the bias of subjective scoring (as in the case of BCS) if used simultaneously (Carter \& Dugdale, 2013). The association between these animal-based morphometric indicators and BCS, has been evaluated in different studies on ponies and horses (Carter et al., 2009; Dudgale et al., 2009, Fernandez et al., 2009; Giles et al., 2014;), but knowledge is still scant where donkeys are concerned.

Moreover, other animal-based morphometric indicators have been proposed in the last few years; many studies have identified that equids, store regional fat especially on the neck, that can remain in donkeys even if the overall condition decreases (Burden, 2012; Burden and Thiemann, 2015). A proposal for a neck score of the adiposity of donkeys exists (Mendoza et al., 2015), but is based on a 0-4 scale, rather than on the 0-5-point scale and it is not associated with all the morphometric variables of the neck, such as the neck circumference (NC) measured at 0.25 and 0.75 of the neck length, the neck height $(\mathrm{NH})$ or the neck thickness $(\mathrm{NT})$ at 0.50 . We therefore propose a new measurement which we refer to as the 'Fatty Neck Score' In addition to the animal-based morphometric indicators used to describe the body condition, other parameters should also be considered. Both internal and external features affect the body condition of animals and the potential influence of these features should be considered in order to understand the complexity of this concept (Resano-Mayor et al., 2016). Age, physiological status and dental health status (Du Toit et al., 2008; Du Toit, Burden \& Dixon, 2009) can be considered as animal-based indicators that can influence the body condition.

Moreover, because the owners play an important role in maintaining the body condition, it is also 
120 important to assess their perception of the body condition in terms of BCS (Hemsworth \&

121 Coleman, 2000).

122 The aim of the study was to identify which morphometric measurements are most practical to

123 describe the body conditions of lactating donkey.

124 To achieve this goal, we assessed the relationship between body condition score, body

125 measurements, and we tested new measurements, namely the fatty neck score, and a simple

126 dental score. A principal component analysis was conducted on the animal-based indicators that

127 showed an association with BCS, in order to determine which were most useful in defining the

128 body condition of lactating donkey.

129

130

131

MATERIALS AND METHODS

132

133

134

This paper describes the results of a surveillance program that was set up by the regional health authorities (regional surveillance working group, Protocol 9641/DB2017, 23/03/12). All

135

136

137

138

139

140

141

142

143

144

145

146

147

148

149

150

the study procedures, none of which involved invasive experimental work, were conducted in the presence of the regional veterinary services. The group was working on the production of regional guidelines on donkey milk production (Regione Piemonte, BU 29 18/07/2013 Code DB2017 D.D. 17 June 2013, no. 461).

\section{Population description}

Monitoring was conducted from May to June 2014 on dairy farms in the North-West of Italy. The study included all the animals present throughout the territory that were milked for the sale of milk. The animals were housed on 6 breeding farms authorized to produce and sell donkey milk, according to the Piedmont Region guidelines (Code DB2017 D.D. 17 June, 2013, no. 461). All the donkeys included in the study were bred on semi-extensive/extensive farms, and had free access to drinking water and forage.

\section{Animal-based morphometric indicators}

Morphometric indicators of the body

The following body measurements were assessed for each animal, using a soft measuring tape (see Fig. 1, Fig. 2): i) body length (OP, olecranon tuber-pinbone), measured from the back of the shoulder (olecranon tuber) to the pin bone (ischiatic tuberosity); ii) body length ( $\mathrm{SH}$, 
151 shoulder-hip), measured from the shoulder point (intermediate tubercle of the humerus) to the

152 hip (tuber coxae); iii) heart girth (HG), measured as the circumference of the body, at the point

153 caudal to the elbow (olecranon tuber) $2 \mathrm{~cm}$ behind the highest point of the withers; iv) abdominal

154 circumference (AC), measured at two-thirds of the distance from the shoulder point to the hip.

155 The body weight (BW) was calculated using the formula proposed by Pearson and Ouassat

156 (2000): BW $\left.(\mathrm{kg})=[\mathrm{HG} \mathrm{cm})^{2.12} \times \mathrm{OP}(\mathrm{cm})^{0.688}\right] / 3801$

157 Four independent expert evaluators (researchers), rated the body condition score (BCS) on a

158 scale of 1 (poor) to 5 (obese), using a previously established scoring system (Burden, 2012). The

159 median of the 4 scores, rounded to the nearest whole or half-score increment, was used for the

160 analysis. The owner was also asked to evaluate the BCS according to the same 5-point scale

161 proposed by Burden (2012). Both the expert evaluators and the owners scored the animals with

162 the help of a chart in which the different scores were defined, and rated the BCS after palpation

163 and a visual assessment of the animals.

164 Morphometric indicators of the neck

165 The following neck measurements were conducted for of each animal, using a soft

166 measuring tape: i) neck circumference (NC), measured at $0.25,0.50$ and 0.75 of the total neck

167 length; ii) neck height ( $\mathrm{NH})$, measured at 0.50 of the neck length, taken from the dorsal midline

168 of the neck to the point of the estimated differentiation between the crest (tissue apparent above

169 the ligamentum nuchae) and the neck musculature; and iii) neck thickness (NT), was introduced

170 considering anecdotal evidence that the neck of a donkey tends to droop sideways to the crest of

171 the neck; it was measured from one side of the neck to the other at 0.50 of the neck length, taken

172 from the point of the estimated differentiation between the crest and the neck musculature; iv)

173 neck length (NL), measured from the poll to the highest point of the withers.

174 After the evaluation of the BCS, the expert evaluators judged the neck fat deposition. They used

175 the fatty neck score (FNS), developed considering the 0-5 point scale that is reported in Table 1,

176 which was based on the one that had previously been proposed for horses (Carter et al., 2009).

177 The median of the 4 scores, rounded to the nearest whole or half-score increment, was used for

178 the analysis.

179 Dental score assessment

180 The dental condition of the donkeys was measured on a scale of 0 to 2 , by the same group 181 of expert evaluators. Since it is somewhat difficult to open and look inside a donkey's mouth, the 
182 scale was based on simple evaluations that included the appearance of the incisors, palpation of

183 the cheek teeth to identify dental abnormalities, such as sharp points and hooks, quidding and

184 inability to chew. A scale of 0 was used to indicate "normal dental conditions" (good incisors, no

185 sharp points-hooks, no quidding), 1 was used to indicate "discrete dental conditions" (the

186 presence of sharp points or hooks, but still good chewing ability) and 2 was adopted to indicate

187 "poor dental conditions" (the presence of damaged incisors and/or the presence of sharp points

188 and hooks with quidding).

189

190

Statistical analyses

191 The statistical analyses were performed with the IBM SPSS Statistics 21 software (SPSS

192 Inc., Chicago, USA) and PAST (version 3.14). The median (interquartiles) and mean values ( \pm

193 standard deviation, SD) were calculated for the following parameters: age, month of lactation

194 and body measurements.

195 The following indices were calculated: mean NC (average of $0.25 \mathrm{NC}, 0.50 \mathrm{NC}, 0.75 \mathrm{NC}$ ),

196 0.50NC:NL, mean NC:NL, 0.50NC:NH, Mean NC:NH, 0.50NC:NT, mean NC:NT, AC:BW,

197 AC:HG, AC:OP, AC:SH, HG:BW, HG:OP and HG: SH. The possible associations between the

198 variables were quantified using Spearman's rank correlation coefficient $\left(\mathrm{r}_{\mathrm{s}}\right)$, and the Bonferroni

199 correction was applied to adjust the $p$ values for multiple comparisons. A principal component

200 analysis (PCA) (correlation matrix) was applied to reduce the variables to factors; data

201 assumption for multivariate normality was checked by means of Keiser-Meyer-Olkin (KMO)

202 and Barlett tests, which were performed to test the suitability of the data for structure detection.

203 Only factors with higher Eigen values than 1 were considered. Only animal-based indicators that

204 had a significant correlation with BCS, according to $r_{s}$, were included in the PCA. Among them

205 only the variables that were easy to perform in the field were included (FNS, BCS, NH, NT and

206 dental score). The lactation month and age were also included since they are physiological

207 feature of the animals.

208 The inter-observer reliability of the expert evaluator and owners in their assessment of BCS and

209 FNS was evaluated by means of intra-class correlations, and by means of Kendall's Coefficient

210 of concordance.

211

212

RESULTS 
213

214

215

216

217

218

219

220

221

222

223

224

225

226

227

228

229

230

231

232

233

234

235

236

237

238

239

240

241

242

243

\section{Population description}

Fifty-three healthy lactating donkeys of various breeds, including 7 Martina Franca, 10 Ragusano, 2 Romagnolo and 34 crossbreeds, with a median age of 9 years (range: 7-12 years), an estimated mean body weight (BW) of $314.5 \mathrm{~kg}$ (range: 269-350) and a mean month of lactation of $4 \pm 3$ months, were evaluated.

Fatty neck score definition and its association with morphometric measurement of the neck

Among the considered morphometric parameters, FNS was found to be positively correlated to $0.50 \mathrm{NH}$ and $0.50 \mathrm{NT},(p<0.001), 0.50 \mathrm{NC}(p=0.002), 0.75 \mathrm{NC}(p=0.003)$, mean $\mathrm{NC}(p<0.001)$ and negatively correlated to the mean NC:NH and mean NC:NT, $0.50 \mathrm{NC}: \mathrm{NT}$ and $0.50 \mathrm{NC}: \mathrm{NH}$ ratios $(p<0.001)$ (Table 2$)$.

\section{Association of BCS with morphometric measurements and dental score}

The median BCS and FNS of the lactating donkeys were 2.5 (2-3) and 2.5 (1.5-3), respectively. No significant correlations were found between the morphometric measurements and BCS (Table 3). However, our results highlighted a positive and significant correlation between BCS and FNS $(p<0.001$; Table 3).

Kendall's coefficient of concordance between the expert evaluators' and the owners' scores for the BCS was low (0.28), thus indicating a substantial disagreement in their evaluations. The owner gave higher score to the animals, result that was clearly at odds with the evaluations of the expert evaluators, who were trained in BCS scoring; it was found that donkeys with a larger abdominal circumference received a higher BCS since a significant, but also rather low correlation was found between AC and the owners 'estimations of BCS $\left(\mathrm{r}_{\mathrm{s}}=0.41, p=0.002\right)$. The intra-class correlation coefficients was calculated to estimate the reliability of the scores (BCS, FNS), when assigned by expert evaluators. The assigned scores showed an intra-class correlation coefficient of 0.85 for BCS (95\% confidence interval 0.80- 0.92$)$ and of 0.58 (95\% confidence interval 0.30-0.76) for FNS.

A Chi-squared test $(p<0.05)$ indicated a significant relationship between BCS and the dental score. The donkeys that had a BCS score of 1 and 2 showed the highest proportion of score 2 (poor dental conditions), when assessed on the basis of the dental score.

\section{PCA analysis of animal-based indicators of the body condition}

A principal component analysis (PCA) was performed in order to represent the variability of the selected animal-based indicators (BCS, FNS, dental score, NT, NH, age and month of 
244 lactation) of the 53 lactating donkeys. The suitability of the data for PCA was evaluated (KMO =

245 0.80; Barlett's test, $p<0.001$ ). Figure 3 shows that PCA separated the classes of BCS on the first 246 principal component (PC1): component 1 explains 54\% of variance of the data, and component 2 247 another $18 \%$, for a total of $72 \%$ of variability. PC1 was positively correlated to FNS, BCS, NT 248 and to NH, with high positive loadings. Conversely, the presence of dental abnormalities showed 249 high negative loadings on PC1, thus indicating that the animals with high BCS had high FNS, as 250 well as poor dental conditions. Table 4 shows the loadings of the variables of the first and second 251 252 principal components, and shows how each variable contributes to each component. It is not possible to graphically show that the subjects belonging to a specific breed were grouped separately or as outliers for BCS in the principal component analysis.

\section{DISCUSSION}

The body condition is generally estimated by considering various types of morphological or physiological measurements (Labocha and Hyes, 2012). The most common animal-based indicator used to assess the body condition of donkeys is the body condition score (BCS), which is proposed as an index of the overall adiposity. In fact, the BCS system includes appraisal, both visually and by means of palpation, of the adipose tissue, which is then scored either on a 5-point or a 9-point scale (Pearsonand Ouassat, 2000; Burden, 2012). Correlations between the BCS, as

262

263

264

265

266

267

268

269

270

271

272

273

274 an index of the overall adiposity, and animal-based morphometric measurements have already been demonstrated in horses (Carter et al., 2009; Dugdale et al., 2011). However, in the present study, when the proposed animal-based morphometric indicators of the body were analysed, no correlation was found between them and the BCS. This has led the authors to question the suitability of the morphometric measurements used in the study as indicators of the overall adiposity of this species. This lack of correlation could be due to several factors: when employing BCS to measure the overall adiposity of the animal, it is necessary to bear in mind that there is a certain level of subjectivity in the assignment of scores (Carter et al., 2009) and, according to Dugdale et al. (2011), there is a loss of sensitivity of subjective BCS systems in overweight subjects. Another factor is related to the fact that donkeys are not small horses, although they both belong to the Equidae family; donkeys also differ from each other in many ways, particularly as far as their anatomical variations and physical conformations are concerned (Burden and Thiemann, 2015). This variability is thus not only interspecific, it is also 
275 intraspecific. In addition, Kugler et al. (2008) stated, on the basis of an overview of the current

276 donkey population in Europe, that most animals are crossbreeds and cannot be categorized into

277 specific breeds. The donkeys in the present study were also mainly crosses, unlike most other

278 livestock species, in which pedigree-breeding and high genetic selections usually exist. Cross

279 breeding in the donkey population has resulted in diversity amongst individuals, in particular, for 280 example in body size (Fig. 4). Therefore, morphometric measurements, in spite of being suitable

281 for horses and ponies and although they are easy to perform, cannot be considered an objective

282 alternative to the evaluation of the body condition of lactating donkeys. Although no correlation

283 was found between the morphometric measurements and BCS, when evaluated by the expert

284 evaluators, producers usually rely on morphometric measurements to evaluate BCS.

285 Interestingly, when the donkey owners were asked to evaluate the BCS, they gave higher score

286 to the animals result that was clearly at odds with the evaluations of the expert evaluators, who

287 were trained in BCS scoring; it was also found that donkeys with a larger abdominal

288 circumference received a higher BCS and this can be explained by the fact that the owners were

289 probably misled by the innate anatomical conformation of the abdomen. In fact, donkeys are

290 anatomically characterized by a pendulous abdomen (Pearson et al., 2001; Burden, 2012).

A new, animal-based morphometric indicator of the neck has been analysed in the present

292 study. Regional fat adiposity could be an important indicator that has not yet been included in

293 body condition evaluations. To this end, a new scoring system, based on the assessment of the morphology of the fat deposition, and which has been called Fatty Neck Score (FNS), has been proposed. This new scoring system is based on an evaluation of neck thickness (NT). This adipose tissue of donkeys, unlike that of other equids, tends to droop on both sides of the crest of the neck (Burden, 2012). Unlike previous studies conducted on horses, the FNS was not positively correlated to the $0.50 \mathrm{NC}: \mathrm{NH}$, the mean $\mathrm{NC}: \mathrm{NH}$, the $0.50 \mathrm{NC}: \mathrm{NT}$, or the mean NC:NT ratios. Instead, FNS was significantly and negatively correlated to these ratios. This result can be explained by considering that the shape of the neck of a donkey is different from that of a horse. The shorter neck and the more protruding manubrium of the donkey support a heavy skull (Burden and Thiemann, 2015), and this leads to the development of a remarkably thick cutaneus colli muscle, which even covers the middle one-third of the jugular furrow (Burnham, 2002). In the present study, it has been possible to develop an objective scale of reference for FNS in a population of lactating donkeys (Table 1). FNS it is a morphometric index of regional fat 
306 deposition but even if correlated to BCS, it can be independent of the overall adiposity status, 307 since it can remain even when the overall body weight decreases (Burden, 2012; Burden and 308 Thiemann, 2015). In addition, this regional adiposity could play a different role in donkeys from 309 the role it plays in horses. It is well known that the Cresty Neck Score in horses and ponies 310 (Carter et al., 2009; Giles et al., 2015) can be linked not only to the body condition, but also to 311 the metabolic status, but this aspect has not yet been characterized in donkeys, and further 312 studies are necessary to understand its metabolic purpose.

The mechanism for the overall determination of the body condition is too complex to be explained only through a correlation and univariate analysis. PCA was therefore used to indicate

315

316

317

318

319

320

321

322

323

324

325

326

327

328

329

330

331

332

333

334

335

336

the most useful components to define the body condition of lactating donkeys. It was performed on animal-based indicators which can be performed easily on animals (FNS, NH, NT) and that showed a significant correlation to BCS. Age and month of lactation were also included. PC1 displayed high loadings for the FNS, BCS and NH and FNS was the main variable that contributed to $\mathrm{PC} 1$, thus suggesting that it is important for the description of the body condition. The results obtained in the present study make it possible to speculate that FNS could be a useful farm animal-based indicator, in addition to BCS, in defining the body condition of donkeys. Nevertheless, further studies are needed to investigate whether there is a link between FNS and the hormonal status of donkeys and disease. Furthermore, the findings of the present study suggest that dental disorders should be included when evaluating the body condition of lactating donkeys. According to Rodrigues et al. (2013), dental disorders, such as sharp points and hooks, are recognized as major, but often unnoticed and therefore often untreated, disorders of equids. In addition, several studies have demonstrated that dental disorders in donkeys are associated with poor BCS, weight loss (Du Toit et al., 2008; Du Toit et al., 2009) and colic (Cox et al., 2009). These results are supported by the present results, which indicate a significant inverse relationship between BCS and oral conditions.

\section{CONCLUSIONS}

A new scoring system, called Fatty Neck Score (FNS), has been proposed in the present study. The results underline the fact that measurement of body condition is complex task. According to PCA, it is necessary to evaluate FNS, BCS and furthermore the present study suggest that the dental condition of donkeys should also be considered as a farm-based indicator. However, in 
337

338

339

340

341

342

343

344

345

346

347

348

349

350

351

352

353

354

355

356

357

358

359

360

361

362

363

364

365

366

367

368

order to evaluate which animal-based indicators can improve the accuracy of the evaluation of the body condition of donkeys, more studies are required, even to understand how training can help to avoid misjudgements of the body condition. The authors believe that caregivers might use BCS, FNS and dental scores together as a tool for the evaluation of the body condition of donkeys, as long they are trained in accurate evaluation. The present results apply to those animals that are specifically bred for milk production.

\section{REFERENCES}

Bruynsteen L., Moons CPH., Janssens GPJ., Harris PA., Vandevelde K., Lefère L., Duchateau L., Hesta M. 2015. Level of energy restriction alters body condition score and morphometric profile in obese Shetland ponies. Veterinary Journal 206:61-66. DOI: 10.1016/j.tvj1.2015.06.006.

Burden F. 2012. Practical feeding and condition scoring for donkeys and mules. Equine Veterinary Education 24:589-596. DOI: 10.1111/j.2042-3292.2011.00314.x.

Burden F., Thiemann A. 2015. Donkeys are different. Journal of Equine Veterinary Science 35:376-382. DOI: 10.1016/j.jevs.2015.03.005.

Burnham, S L. 2002. Anatomical differences of the donkey and mule. Proceeding Annual Convention AAEP. 48:102-109.

Cappai, MG, Picciau M, Pinna W. 2013. An integrated approach towards the nutritional assessment of the Sardinian donkey: a tool for clinical nutritionists. Italian Journal of animal science 12:182-185. DOI:10.4081/ijas.2013.e29

Carter RA., Geor RJ., Burton Staniar W., Cubitt TA., Harris PA. 2009. Apparent adiposity assessed by standardised scoring systems and morphometric measurements in horses and ponies. Veterinary Journal 179:204-210. DOI: 10.1016/j.tvj1.2008.02.029.

Cavallarin L., Giribaldi M., Soto-Del Rio M de los D., Valle E., Barbarino G., Gennero MS., Civera T. 2015. A survey on the milk chemical and microbiological quality in dairy donkey farms located in NorthWestern Italy. Food Control 50:230-235. DOI: 10.1016/j.foodcont.2014.08.019.

Cox R, Proudman CJ, Trawford AF, Burden F, Pinchbeck GL. 2007. Epidemiology of impaction colic in donkeys in the UK.. BMC Veterinary Research 2;3-1. DOI: 10.1186/1746-6148-31 
369

400 401

D’Alessandro AG., Martemucci G. 2012. Lactation curve and effects of milking regimen on milk yield and quality, and udder health in Martina Franca jennies (Equus asinus). Journal of Animal Science 90:669-681. DOI: 10.2527/jas.2011-4283.

du Toit N., Burden F a., Dixon PM. 2009. Clinical dental examinations of 357 donkeys in the UK. Part 2: epidemiological studies on the potential relationships between different dental disorders, and between dental disease and systemic disorders. Equine veterinary journal 41:395-400. DOI: 10.2746/042516409X368903.

Du Toit N., Gallagher J., Burden FA., Dixon PM. 2008. Post mortem survey of dental disorders in 349 donkeys from an aged population (2005-2006). Part 1: prevalence of specific dental disorders. Equine veterinary journal 40:204-8. DOI: 10.2746/042516408X266060.

Dugdale AHA., Curtis GC., Harris PA., Argo CM. 2011. Assessment of body fat in the pony: Part I. Relationships between the anatomical distribution of adipose tissue, body composition and body condition. Equine Veterinary Journal 43:552-561. DOI: 10.1111/j.2042-3306.2010.00330.x.

Elmadfa I., Meyer AL. 2014. Developing suitable methods of nutritional status assessment: a continuous challenge. Advances in nutrition (Bethesda, Md.) 5:590S-598S. DOI: 10.3945/an.113.005330.

Faye,B, , Konuspayevab G. 2012. The sustainability challenge to the dairy sector - The growing importance of non-cattle milk production worldwide. International Dairy Journal 2:50-56. DOI: http://dx.doi.org/10.1016/j.idairyj.2011.12.011

Giles SL., Nicol CJ., Rands SA., Harris PA. 2015. Assessing the seasonal prevalence and risk factors for nuchal crest adiposity in domestic horses and ponies using the Cresty Neck Score. BMC veterinary research 11:13. DOI: 10.1186/s12917-015-0327-7.

Giles SL., Rands SA., Nicol CJ., Harris PA. 2014. Obesity prevalence and associated risk factors in outdoor living domestic horses and ponies. PeerJ 2:e299. DOI: 10.7717/peerj.299.

Heidler B., Aurich JE., Pohl W., Aurich C. 2004. Body weight of mares and foals, estrous cycles and plasma glucose concentration in lactating and non-lactating Lipizzaner mares. Theriogenology 61:883-893. DOI: 10.1016/S0093-691X(03)00279-6.

Hemsworth PH., Coleman GJ., Barnett JL., Borg S. 2000. Relationships between human-animal interactions and productivity of commercial dairy cows. Journal of Animal Science 78:2821-2831. DOI: /2000.78112821x.

Ireland JL., McGowan CM., Clegg PD., Chandler KJ., Pinchbeck GL. 2012. A survey of health care and disease in geriatric horses aged 30years or older. Veterinary Journal 192:57-64. 
402

403

404

405

406

407

408

409

410

411

412

413

414

415

416

417

418

419

420

421

422

423

424

425

426

427

428

429

430

431

432

433

434

435

Kugler W, Grunenfelder HP, Broxham E. 2008. Donkey Breeds in Europe: Inventory, Description, Need for Action, Conservation. Report 2007/2008. Available at http://www.save-foundation.net/pdf/donkey.pdf (2008) (Accessed 15 march 2012).

Labocha MK, Haye JP. 2012 Morphometric indices of body condition in birds: a review. Journal of Ornithology, 153:1-22. DOI:10.1007/s10336-011-0706-1.

Labocha MK, Schutz H, Hayes JP. 2013. Which body condition index is best? Oikos, 123:111119 DOI: $10.1111 /$ j.1600-0706.2013.00755.x

Martinson KL., Coleman RC, Rendahl AK, Fang Z, McCue ME. 2014. Estimation of body weight and development of a body weight score for adult equids using morphometric measurements. Journal of Animal Science 92:2230-2238. DOI: 10.2527/jas.2013-6689.

Martinson KL., Coleman RC., Rendahl AK., Fang Z., McCue ME. 2014. Estimation of body weight and development of a body weight score for adult equids using morphometric measurements. Journal of Animal Science 92:2230-2238. DOI: 10.2527/jas2013-6689.

Mendoza FJ., Estepa JC., Gonzalez-De Cara CA., Aguilera-Aguilera R., Toribio RE., PerezEcija A. 2015. Energy-related parameters and their association with age, gender, and morphometric measurements in healthy donkeys. Veterinary Journal 204:201-207. DOI: 10.1016/j.tvj1.2015.03.004.

Monti G., Bertino E., Muratore MC., Coscia A., Cresi F., Silvestro L., Fabris C., Fortunato D., Giuffrida MG., Conti A. 2007. Efficacy of donkey's milk in treating highly problematic cow's milk allergic children: An in vivo and in vitro study. Pediatric Allergy and Immunology 18:258-264. DOI: 10.1111/j.1399-3038.2007.00521.x.

Monti G., Viola S., Baro C., Cresi F., Tovo PA., Moro G., Ferrero MP., Conti A., Bertino E. 2012. Tolerability of donkey's milk in 92 highly-problematic cow's milk allergic children. Journal of biological regulators and homeostatic agents 26:75-82.

Mulligan FJ., O\&apos;Grady L., Rice DA., Doherty ML. 2006. A herd health approach to dairy cow nutrition and production diseases of the transition cow. Animal Reproduction Science 96:331-353. DOI: 10.1016/j.anireprosci.2006.08.011.

Pearson AR Ouassat M. 2000. A Guide to Live Weight Estimation and Body Condition Scoring of Donkeys. Centre for Tropical Veterinary Medicine, Edinburgh, UK. Aviable at http://www.fao.org/fileadmin/user_upload/drought/docs/Condition\%20Scoring\%20Donkeys.p df

Pearson R a., Archibald RF., Muirhead RH. 2007. The effect of forage quality and level of feeding on digestibility and gastrointestinal transit time of oat straw and alfalfa given to ponies and donkeys. British Journal of Nutrition 85:599. DOI: 10.1079/BJN2001321. 
436

Pearson R a., Ouassat M. 1996. Estimation of the liveweight and body condition of working donkeys in Morocco. The Veterinary record 138:229-33. DOI: 10.1136/vr.138.10.229.

Pleasant RS., Suagee JK., Thatcher CD., Elvinger F., Geor RJ. 2013. Adiposity, plasma insulin, leptin, lipids, and oxidative stress in mature light breed horses. Journal of Veterinary Internal Medicine 27:576-582. DOI: 10.1111/jvim.12056.

Quaresma M., Payan-Carreira R., Silva SR. 2013. Relationship between ultrasound measurements of body fat reserves and body condition score in female donkeys. Veterinary Journal 197:329-334. DOI: 10.1016/j.tvj1.2012.12.031.

Resano-Mayor J, Hernández-Matías A, Real J, Parés F, Moleón M, Mateo R, Ortiz-Santaliestra ME. 2016. The influence of diet on nestling body condition of an apex predator: a multibiomarker approach. Journal of Comparative Physiology B. 186:343-62. DOI: 10.1007/s00360-016-0967-3.

Roche JR., Macdonald KA., Burke CR., Lee JM., Berry DP. 2007. Associations among body condition score, body weight, and reproductive performance in seasonal-calving dairy cattle. Journal of Dairy Science 90:376-91. DOI: 10.3168/jds.S0022-0302(07)72639-5.

Rodrigues JB., Dixon PM., Bastos E., San Roman F., Viegas C. 2013. A clinical survey on the prevalence and types of cheek teeth disorders present in 400 Zamorano-Leonés and 400 Mirandês donkeys (Equus asinus). The Veterinary record 173:581. DOI: $10.1136 /$ vr.101747.

Trinchese G., Cavaliere G., Canani RB., Matamoros S., Bergamo P., De Filippo C., Aceto S., Gaita M., Cerino P., Negri R., Greco L., Cani PD., Mollica MP. 2015. Human, donkey and cow milk differently affects energy efficiency and inflammatory state by modulating mitochondrial function and gut microbiota. Journal of Nutritional Biochemistry 26:11361146. DOI: 10.1016/j.jnutbio.2015.05.003.

Vincenzetti S, Polidori P, Vita A. 2007 Nutritional characteristias of donkey's milk protein fraction. In: Ling RR, ed. Dietary Protein Research Trends. New York: Nova Science Publishers, Inc. Animal Research, 67-78. 


\section{Table 1 (on next page)}

Fatty Neck Score (FNS) for donkeys

Donkey neck images were drawn by Federica Raspa 


\begin{tabular}{|c|c|c|c|}
\hline Score & $\begin{array}{l}\text { Illustrations of the } \\
\text { individual fatty neck score }\end{array}$ & Description & $\begin{array}{l}\text { Neck thickness } \\
\text { range according } \\
\text { to FNS (in } \mathrm{cm} \text { ) }\end{array}$ \\
\hline 0 & & $\begin{array}{l}\text { Neck: thin with the absence of a visible and } \\
\text { palpable crest. }\end{array}$ & $<14$ \\
\hline 1 & & $\begin{array}{l}\text { Neck: thin with no visible crest, but a slight } \\
\text { filling felt upon palpation. }\end{array}$ & $>14-19$ \\
\hline 2 & & $\begin{array}{l}\text { Neck: with a moderate deposition of fat. } \\
\text { Noticeable appearance of a crest, with fat } \\
\text { deposited fairly evenly from the poll to the } \\
\text { withers. Crest: easily cupped in one hand } \\
\text { and easily bent from side to side. }\end{array}$ & $>19-22$ \\
\hline 3 & & $\begin{array}{l}\text { Neck: enlarged and thickened. Crest: } \\
\text { palpable from the poll to the withers, filling } \\
\text { a cupped hand, and beginning to form } \\
\text { longitudinal fat deposits on both sides of the } \\
\text { neck. }\end{array}$ & $>22-27$ \\
\hline 4 & & $\begin{array}{l}\text { Neck: very enlarged and thickened. Crest: } \\
\text { grossly thickened with fat deposits from the } \\
\text { poll to the withers, forming longitudinal } \\
\text { bands of fat on both sides of the neck. Crest } \\
\text { cannot be bent easily from side to side. }\end{array}$ & $>27-34$ \\
\hline
\end{tabular}


5

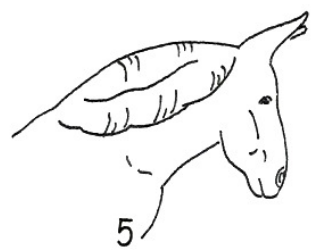

Neck: very enlarged and thickened. Crest: very thickened with hard fat deposits, $>34$ rounded along both sides of the neck.

1 


\section{Table 2 (on next page)}

Association of the fatty neck score (FNS) with the morphometric measurements of neck adiposity

${ }^{a}$ Spearman rank correlation coefficient.

${ }^{\mathrm{b}} P$ value

* Bonferrroni-corrected statistically significant

${ }^{\mathrm{c}}$ Neck circumference $(\mathrm{NC})$ at $0.25-0.50-0.75$ of the neck lenght (NL);

${ }^{\mathrm{d}}$ Average of $0.25 \mathrm{NC}, 0.50 \mathrm{NC}, 0.75 \mathrm{NC}$.

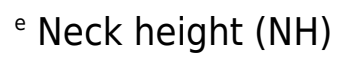

${ }^{\mathrm{f}}$ Neck thickness (NT) 
1

\begin{tabular}{|c|c|c|}
\hline \multirow{2}{*}{ Morphometric measurements } & \multicolumn{2}{|c|}{ FNS $($ no $=53)$} \\
\hline & $\mathrm{r}_{\mathrm{s}}^{\mathrm{a}}$ & $\mathrm{p}^{\mathrm{b}}$ \\
\hline $0.25 \mathrm{NC}^{\mathrm{c}}$ & 0.37 & 0.007 \\
\hline $0.50 \mathrm{NC}^{\mathrm{e}}$ & 0.42 & $0.002^{*}$ \\
\hline $0.75 \mathrm{NC}^{\mathrm{c}}$ & 0.40 & $0.003 *$ \\
\hline Mean NC d & 0.44 & $0.001 *$ \\
\hline $0.50 \mathrm{NC}: \mathrm{NL}$ & 0.35 & 0.011 \\
\hline Mean NC:NL & -0.01 & 0.925 \\
\hline $0.50 \mathrm{NC}: \mathrm{NH}^{\mathrm{e}}$ & -0.58 & $<0.001 *$ \\
\hline Mean NC:NH & -0.83 & $<0.001 *$ \\
\hline $0.50 \mathrm{NH}$ & 0.83 & $<0.001 *$ \\
\hline $0.50 \mathrm{NC}^{\mathrm{NT}} \mathrm{f}^{\mathrm{f}}$ & -0.68 & $<0.001^{*}$ \\
\hline Mean NC:NT & -0.82 & $<0.001 *$ \\
\hline $0.50 \mathrm{NT}$ & 0.83 & $<0.001 *$ \\
\hline
\end{tabular}

2 


\section{Table 3(on next page)}

Association of the body condition score (BCS) with the morphometric measurements of the body

${ }^{a}$ Spearman rank correlation coefficient.

${ }^{\mathrm{b}} \mathrm{p}$ values.

* Bonferrroni-corrected statistically significant

${ }^{\mathrm{c} B o d y}$ weight.

${ }^{\mathrm{d}}$ Heart girth.

${ }^{\mathrm{e}}$ Abdominal circunference.

f Shoulder-hip lenght.

${ }^{g}$ Olecranon tuber-pinbone lenght.

${ }^{\mathrm{h}}$ Fatty neck score. 


\begin{tabular}{|c|c|c|}
\hline \multirow{2}{*}{ Morphometric measurements } & \multicolumn{2}{|c|}{ Researchers' BCS $($ no $=53)$} \\
\hline & $\mathrm{r}_{\mathrm{s}}^{\mathrm{a}}$ & $\mathrm{p}^{\mathrm{b}}$ \\
\hline $\mathrm{BW}^{\mathrm{c}}$ & 0.42 & 0.11 \\
\hline $\mathrm{HG}^{\mathrm{d}}$ & 0.16 & 0.27 \\
\hline $\mathrm{AC}^{\mathrm{e}}$ & 0.25 & 0.07 \\
\hline $\mathrm{SH}^{\mathrm{f}}$ & -0.01 & 0.95 \\
\hline OPg & 0.05 & 0.70 \\
\hline $\mathrm{FNSh}^{\mathrm{h}}$ & 0.84 & $<0.001 *$ \\
\hline $\mathrm{AC}: \mathrm{BW}$ & 0.01 & 0.96 \\
\hline $\mathrm{AC}: \mathrm{HG}$ & 0.21 & 0.13 \\
\hline $\mathrm{AC}: \mathrm{OP}$ & 0.24 & 0.08 \\
\hline $\mathrm{AC}: \mathrm{SH}$ & 0.35 & 0.01 \\
\hline HG:BW & -0.10 & 0.49 \\
\hline $\mathrm{HG}: \mathrm{SH}$ & 0.14 & 0.31 \\
\hline HG:OP & 0.06 & 0.69 \\
\hline
\end{tabular}

1 


\section{Table 4 (on next page)}

PCA loadings of selected variables for the monitored lactating donkey population .

${ }^{a}$ Body condition score.

${ }^{b}$ Neck thickness at 0.50 of neck lenght

${ }^{\mathrm{c}}$ Neck heigh at 0.50 of neck lenght

${ }^{\mathrm{b}}$ Fatty neck score. 
1

\begin{tabular}{llc}
\hline \hline & \multicolumn{2}{c}{ Components } \\
\cline { 2 - 3 } & $1(53.69 \%)$ & $2(17.51 \%)$ \\
Age & -0.224 & 0.498 \\
Month of lactation & -0.208 & 0.758 \\
BCS $^{\mathrm{a}}$ & 0.896 & -0.045 \\
$\mathrm{NT}^{\mathrm{b}} 0.50$ & 0.915 & 0.291 \\
$\mathrm{NH}^{\mathrm{c}} 0.50$ & 0.883 & 0.316 \\
FNS $^{\mathrm{d}}$ & & 0.042 \\
Mouth condition & 0.944 & 0.463 \\
\hline
\end{tabular}

2 


\section{Figure 1}

\section{Morphometric measurement of the body}

Blue line: body length from the olecranon tuber to the pin bone (OP); Red line: body length from the shoulder point to that of the hip (SH); Yellow line: heart girth (HG), circumference of the body at the point caudal to the elbow, $2 \mathrm{~cm}$ behind the highest point of the withers; Green line: abdominal circumference (AC) at two-thirds of the distance from the shoulder point to that of the hip.

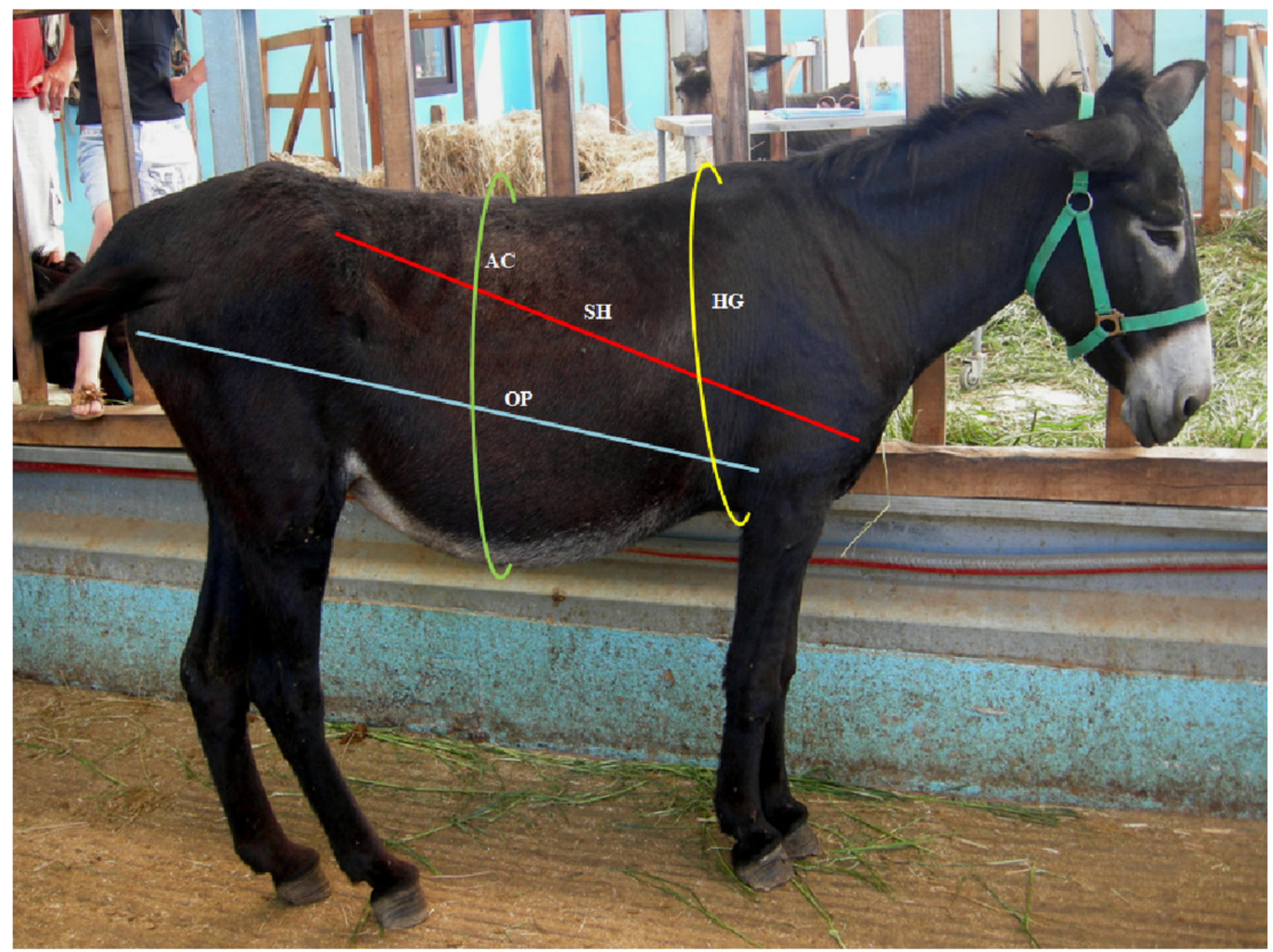




\section{Figure 2}

Morphometric measurement of the neck

Orange line: neck length (NL), from the poll to the highest point of the withers; Pink, yellow and blue lines: neck circumference (NC), at $0.25,0.50$ and 0.75 of the neck length; Red line: neck height (NH), at 0.50 of the neck length, taken from the dorsal midline of the neck to the point of the estimated differentiation between the crest and the neck musculature; Green line: neck thickness (NT), from one side of the neck to the other at 0.50 of the neck length, taken from the point of the estimated differentiation between the crest and the neck musculature

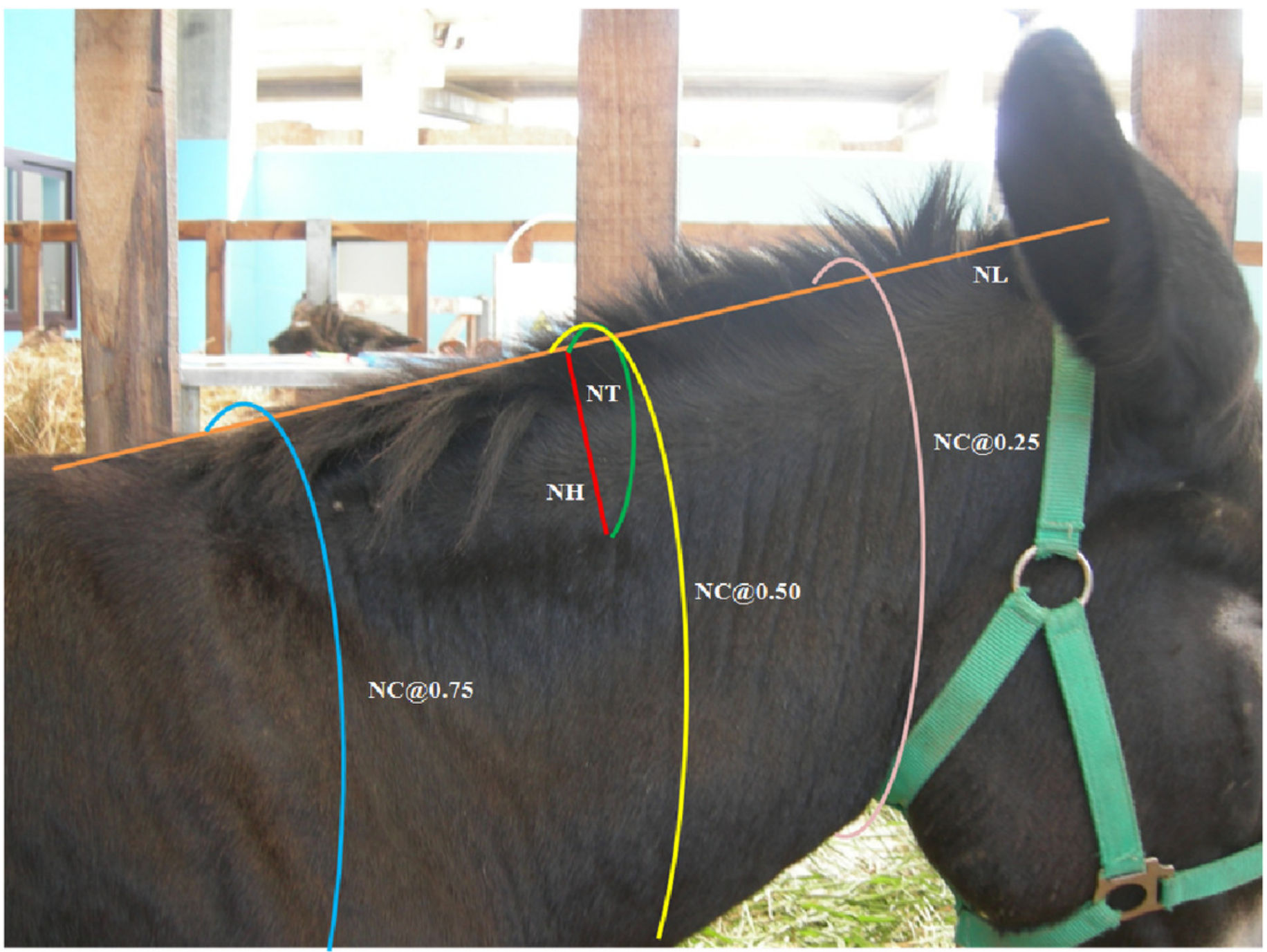


Figure 3

Principal component analysis performed on selected animal-based indicators of the body condition. In order to improve the visualization of the PCA results, different symbols were assigned arbitrarily:

- body condition score (BCS) $<2 ; \triangle B C S<3 ; \square$ BCS $<4$; x BCS $>4$. NT: neck thickness; FNS: fatty neck score; $\mathrm{NH}$ : neck height.

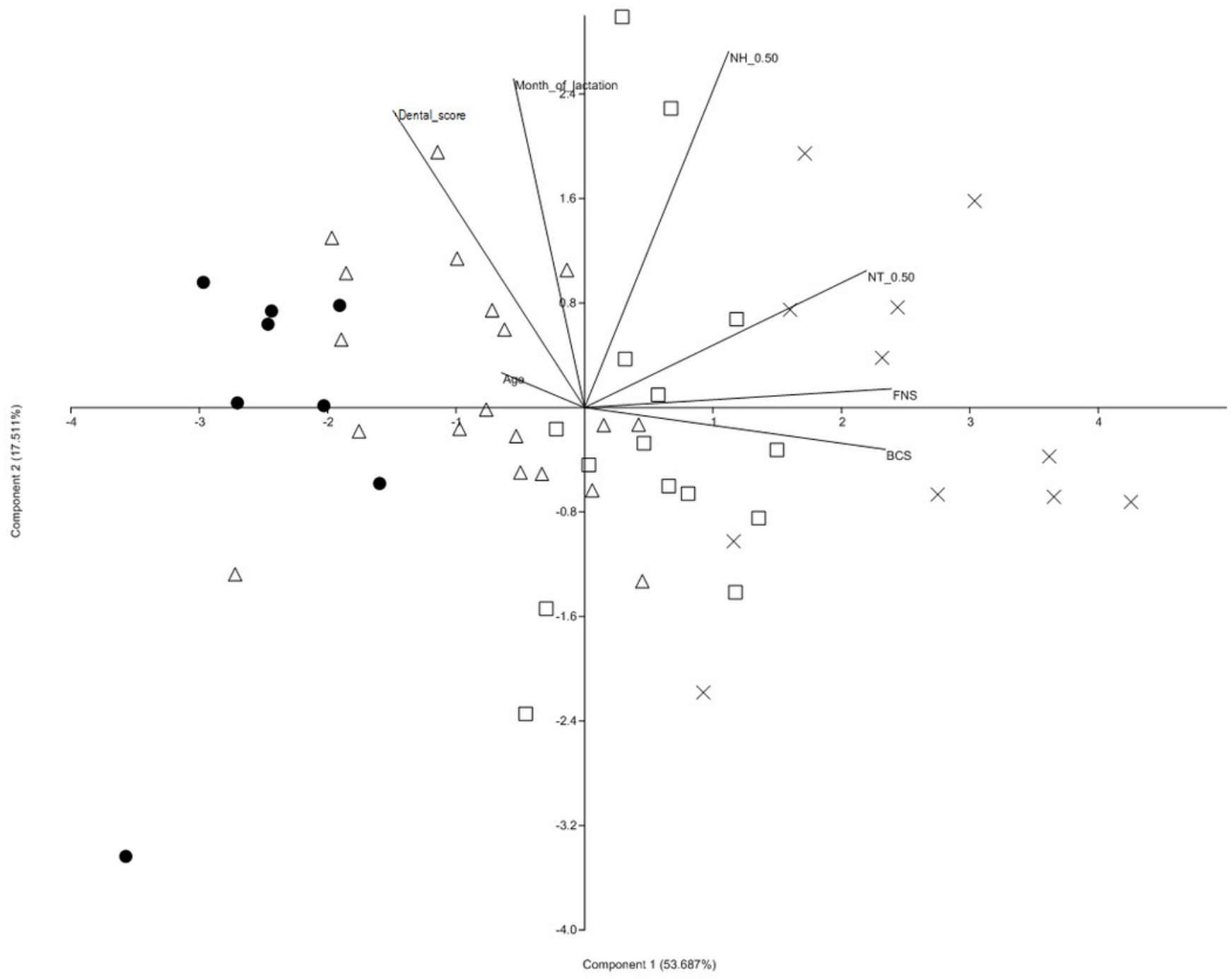




\section{Figure 4}

Diversity of the donkey population in Italian breeding farms

Lactating jennies and their foals at the feeding trough (A) and in a woody open field (B).

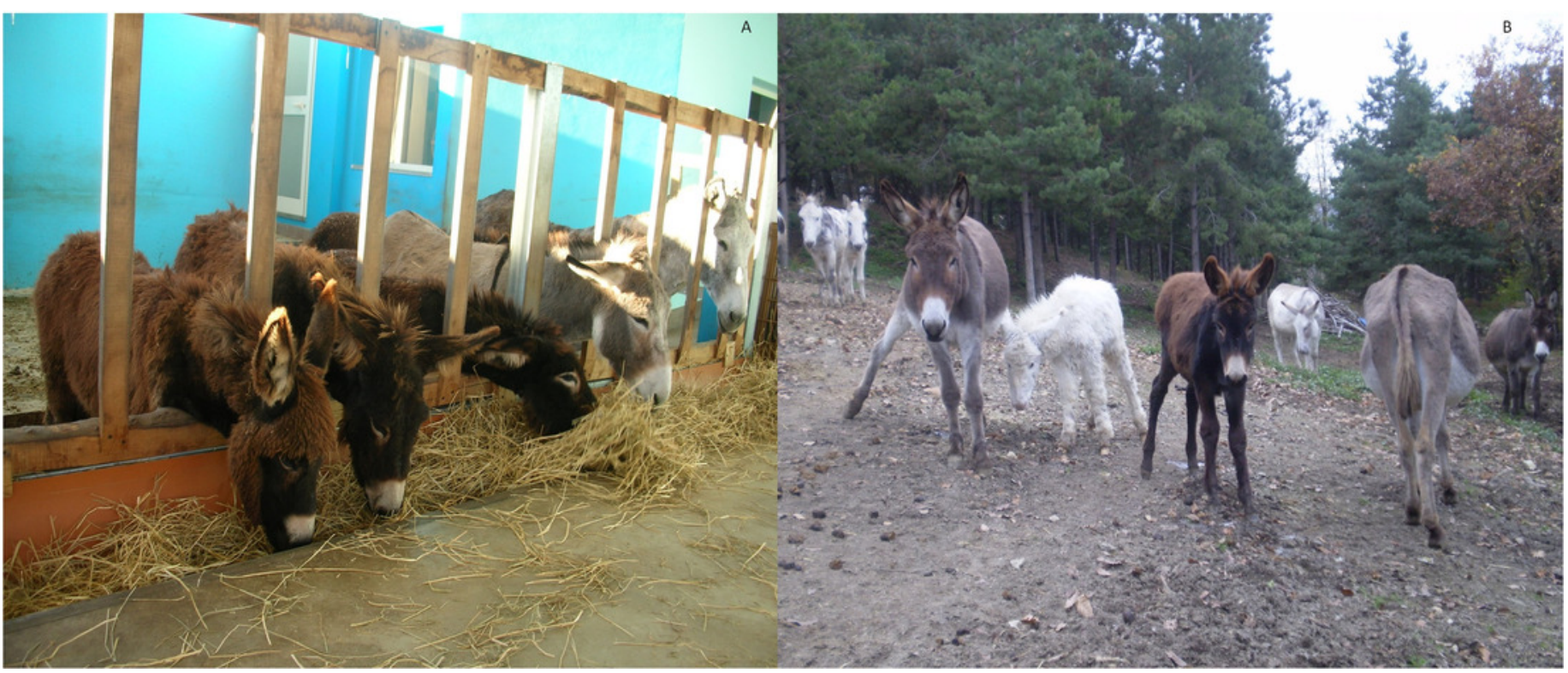

